\section{Litigated conflict over fundamental rights: A static model}

\section{William C. Bunting}

$\mathrm{F}$

undamental rights differ from property rights in that individuals can engage in private bargaining with respect to property rights but not with respect to fundamental rights. ${ }^{1}$ In the traditional Coasian framework, well-defined, legally-enforceable property rights are allocated to a subset of the population. ${ }^{2}$ If transaction costs are sufficiently low, then an efficient equilibrium outcome obtains as a by-product of perfectly-informed, private bargaining among rational, self-interested individuals. Fundamental rights are different, however. The State attaches itself to a single ideological position and commits substantial resources toward enforcing the level of fundamental rights associated with that position. Because parties cannot privately bargain around the state-sponsored allocation of fundamental rights, parties that wish to change the prevailing level of fundamental rights in society must engage in some form of conflict to achieve, from their perspective, a more optimal distribution of rights.

In the static, within-country, game-theoretic model discussed in this article, this conflict over fundamental rights, arising in lieu of private bargaining, takes the form of private civil litigation.

\section{Related literature}

To understand the model of intergroup conflict over fundamental rights within a country, it is useful to consider how it relates to the large international relations literature on war between states. In a seminal article, J.D. Fearon develops three arguments for why states in conflict might fail to settle, ex ante, for bargains that they would otherwise accept ex post. In particular, Fearon posits that (1) war can occur because bargains depend upon factors about which states possess private information, and because states have incentives to misrepresent or misreport this information; (2) wars can derive from commitment problems (states fight because agreements are not binding and because actors have unilateral incentives to defect at a future point in time); and (3) states might be unable to bargain, short of war, because the issues in dispute are not readily divisible. ${ }^{3}$

These explanations do not apply to the within-country case. Unlike warring states, parties in a within-country context do not have the freedom to independently agree to restrict or to expand a given fundamental right. Any bargain struck between parties will be undone by the State, as it is not the contesting parties but the State that fixes fundamental rights. This implies that the parties cannot use the legal system to commit not to breach any private agreement struck between them regarding the allocation of fundamental rights.

The model presented in this article may be viewed as a variant of bargaining in "the shadow of power." ${ }^{, 4}$ In these types of models, actors who have become sufficiently pessimistic about the likelihood of reaching a mutually-agreeable resolution resort to some form of power, be it legal, military, or political. They then use this power to impose a settlement that, in the absence of power, would not otherwise be obtained. For instance, in international negotiations over revisions of a territorial status quo, a state can use military force to secure a new distribution of territory if it becomes sufficiently pessimistic about the likelihood of reaching a mutually-acceptable resolution. ${ }^{5}$

Similarly, a political party (often during democratic transitions) may take to the streets in protest and turn to violence to improve upon an expected outcome to be obtained through legislative bargaining. ${ }^{6}$ In my model of intergroup nonviolent conflict, ideologically-opposed special interest groups turn to the power of private civil litigation to achieve a level of fundamental rights that improves upon what can be obtained solely through democratic means, i.e., through democratic elections.

\section{Summary of results}

The principal question is this: How do changes in the parameters that characterize litigated intergroup conflict over fundamental rights affect social welfare? ${ }^{7}$

The static model discussed here suggests that increased judicial interference is never social welfare-increasing (even when judicial and political biases run in opposite directions, as shown later). ${ }^{8}$ In addition, the analysis identifies a set of parameter values whereby social welfare increases when the extent to which ideological conflict is constitutionalized is decreased (i.e., the more expensive and less effective litigation becomes). For those in position to establish peace and security in areas engulfed by violent conflict, such as Syria presently, this latter result counsels against placing too much weight upon the importance of an independent judiciary 
setting ideology for the country as a whole.

The article proceeds as follows. The first section sets forth, in narrative form, the basic economic model of fundamental rights and their constitutionalization. The second section discusses equilibrium outcomes for both the case of exogenously and endogenously-determined policy platforms in regard to fundamental rights. Social welfare implications are discussed. The third section examines the normative prescription that ideological conflict, under certain circumstances, should be less constitutionalized, i.e., be made more costly and less effective. A few real world examples of the implications of this analysis are briefly examined, including the possible future reconstitution of the judiciary in Syria.

\section{The model in narrative form}

I define conflict over fundamental rights as a contest in civil court between two ideologically opposed groups. The two parameters that characterize the conflict are (1) judicial diversity, defined as the range of feasible conflict outcomes, and (2) the extent to which the legal conflict is constitutionalized, i.e., the extent to which litigation effort is both (a) more or less costly on the margin, and (b) more or less effective or decisive. The constitutionalization parameter is new to the formal political economy literature. ${ }^{9}$

\section{Constitutionalization explained}

The constitutionalization parameter can be interpreted as measuring the extent to which individuals in society are able to contest constitutional rights. In what might be called an authoritarian democracy, for instance, it may be very costly to change the prevailing level of fundamental rights set by a society's chosen leaders (e.g., modern-day Iran). Collective efforts to increase various freedoms of religion or speech, say, may have dire consequences, including State intervention resulting in imprisonment or death. Likewise, in what might be called an anarchic democracy, where the rule of law is weak or nonexistent, it may be that changes in the overall level of fundamental rights can be realized only through autonomous means, including bribery of a local official or judge, and can be accomplished only at significant financial cost or personal risk (e.g., Russia in the mid-1990s). In a constitutional democracy, by contrast, such as the United States or Brazil, contest over fundamental rights that apply equally to all individuals in society is largely a question of constitutional interpretation. Changes in the prevailing level of fundamental rights are attained at relatively low cost; indeed, often times, it is simply a matter of hiring the right attorney.

What can be accomplished through litigated ideological conflict is, by definition, much greater in a constitutional democracy. For example, although a special interest group might succeed in altering certain fundamental rights in an authoritarian democracy, any victory is likely to be small in magnitude. The reason for this is that it will be relatively difficult to persuade a judiciary that exists largely as an extension of an entrenched authoritarian democratic regime to deviate substantially from the ideological tenets espoused and promulgated by that regime. Short of regime change, wrestling a change in fundamental rights by means of private civil litigation from a judiciary that takes its orders from a centralized and repressive authoritarian regime is likely impossible. Likewise, in an anarchic democracy, the impact of a legal victory may be relatively small, in total effect, as it may have no binding quality, vis-à-vis the State's justice system, on the many individuals in such a society that do not follow the law. In a constitutional democracy, by contrast, where contest over fundamental rights takes place between two private litigants before one judicial body in a singular constitutional moment, and the outcome of which then is binding upon all members of society, any change in the level of fundamental rights can be quite large. In the United States, for instance, in winning over a majority of the nine Supreme Court justices, a single litigant can, in a year or two, and at relatively little financial cost, permanently alter the bundle of fundamental rights available to society. The ideological landscape in a constitutional democracy can change quite dramatically, very suddenly, and with very little, if any, bloodshed.

Exogenous and endogenous fundamental rights

The formal analysis starts by assuming that the status quo level of fundamental rights in society is exogenously determined. The analysis identifies three marginal social welfare effects with respect to a change in judicial diversity: (1) increased uncertainty as to judicial outcomes; (2) consumption loss due to the expenditure of costly litigation effort; and (3) changes in the expected level of fundamental rights in society. Initially assuming an unbiased judicial process, the analysis shows that greater judicial diversity is social welfare-increasing if the existing status quo standard is biased in favor of either one of the two special interest groups: The expected benefit of judicial interference, which would move the status quo standard closer to the normative benchmark, exceeds the sum of the cost of increased uncertainty as to future judicia outcomes (where litigants are risk-averse with respect to uncertain future outcomes) and the cost of lower consumption (where individuals, in response to an increase in judicial diversity, substitute litigation expenditure for consumption). ${ }^{10}$ But if the judicial process is biased in favor of either of the two groups, then greater judicial diversity is social welfare-increasing only if the status quo standard is biased in favor of the other special interest group. ${ }^{11}$

The formal model is then extended to allow the status quo level of fundamental rights to be endogenously determined through electoral competition. The analysis employs a standard formal model of Downsian electoral competition and derives announced policy platforms as the unique equilibrium solution to a two-stage politico-conflict game. The comparative-static effects of changes to various 
parameters describing the intergroup conflict follow directly from the derived equilibrium outcome. ${ }^{12}$

The main conclusion of the static model is that electoral candidates strategically respond to an increase in judicial diversity (an increase in the range of feasible judicial outcomes) by shifting announced policy toward the bliss point of their preferred special interest group. In other words, electoral candidates who are biased in favor of a particular special interest group, strategically offset greater adverse judicial interference in the determination of fundamental rights by enacting, in equilibrium, even more extreme, or "polarized," ideological policy platforms that are biased in favor of their preferred interest group. ${ }^{13}$

As a real world example of this type of strategic, forward-looking behavior, consider the landmark United States Supreme Court case, District of Columbia v. Heller [554 U.S. 570 (2008)]. This held that the Second Amendment to the United States Constitution protects an individual's right to possess a firearm for traditionally lawful purposes, such as self-defense within the home and within federal enclaves. The mayor of New York City, Michael Bloomberg, immediately commented that "all of the laws on the books in New York State and New York City" would be allowed by the ruling as "reasonable regulation." In the years following the Heller decision, "anti-gun" politicians similarly have aimed at restricting or otherwise limiting this newly-recognized fundamental right to the private possession of guns. The National Rifle Association and other gun-rights advocates have filed a number of lawsuits in various states. ${ }^{15}$ Under my analysis, all this is a predictable consequence of greater judicial interference in the determination of fundamental rights. As the model predicts, and as Supreme Court Justice Ruth Bader Ginsburg has asserted in the context of abortion rights, ${ }^{16}$ rational political actors will strategically enact legislation designed to offset the effect of subsequent legal conflict, exemplified here in the over 500 state and federal lawsuits that have been filed since the Heller decision seeking to maintain, implement, or further expand the newly-recognized fundamental right to the private possession of firearms. ${ }^{17}$

In addition to the prediction regarding announced policy platforms, two main welfare results are also derived from the model. First, the static model shows that increased judicial diversity is never social welfare-increasing, even if judicial and political biases run in opposite directions. The explanation for this result again lies in taking into account the strategic, forward-looking behavior of rational electoral actors. Recognizing that the influence of a policymaking institution biased against their preferred voter-type has expanded, office-seeking candidates offset expanded judicial influence in the determination of fundamental rights by adopting relatively more extreme, polarized policy positions. These relatively more extreme and socially suboptimal equilibrium policy positions then successfully offset the expected socia welfare-increasing movement in the prevailing level of fundamental rights generated by the subsequent legal conflict. ${ }^{18}$

Second, the model identifies a set of parameter values where decreasing the extent to which ideological conflict is constitutionalized increases social welfare. Given this set of parameter values, policies that facilitate the extent to which ideologically-opposed individuals are able to effectively engage in conflict with one another are to be actively discouraged by the State. Put differently, if the political and judicial institutions that determine the prevailing level of fundamental rights in society can be properly characterized by the set of parameter values isolated in the analysis, then a welfare-maximizing social planner should strive not to promote the judicial resolution of ideological conflict, but, rather, as examined more closely in the next section, to promote, somewhat counter-intuitively, a more costly and less effective conflict over fundamental rights.

\section{Against constitutionalization}

The normative prescription that ideological conflict should be less constitutionalized, i.e., that litigation effort should be more costly and less effective, derives from two facts. First, in equilibrium, the total monetary cost of litigation effort is lowered when it becomes more costly to litigate, and second, in the model conflict is a means by which special interest groups in society use nonelectoral channels to advance their unique ideological agenda: litigation becomes a suboptimal substitute for electoral politics. Now, the capacity to use courts to advance ideological objectives, as an alternative to political conflict, is likely to increase social welfare if courts are fair and benign. But if courts are not fair or benign, and do not necessarily act in ways that serve to promote the greater social good, as literature documents, ${ }^{19}$ then a country less like the United States in terms of how ideology is determined, and more like China (i.e., a country in which ideological conflict is relatively less constitutionalized) may be more likely to implement the socially-optimal level of fundamental rights.

To repeat, when courts cannot be relied upon to implement optimal outcomes, a welfare-maximizing social planner should seek to make litigated conflict more costly and less effective. Under these circumstances, legal conflict can be characterized as a means by which those who have power-not necessarily in terms of control over the State power apparatus, but in terms of the capacity to defeat ideologically-opposed groups in a court of law-use that power to circumvent socially-optimal democratic outcomes. By making the legal conflict less constitutionalized (making litigation more expensive and less decisive), it is now relatively more difficult for those who possess an advantage in legal conflict to use that advantage to modify optimal policy outcomes generated by a democratic electoral process. To reiterate, provided certain conditions hold true, the analysis advocates, somewhat counter-intuitively, for an authoritarian or anarchic democracy, rather than a constitutional democracy, as a better and more effective means by which to protect and safeguard important fundamental rights in society. 


\section{District of Columbia v. Heller}

As an example, consider again the case of District of Columbia v. Heller. The formal model implies that if the political and judicial bias parameters run in the same direction, which I believe was true at the time Heller was decided, then increasing the extent to which ideological conflict in society is constitutionalized is social welfare-decreasing. Specifically, the analysis suggests that the gun-control issue would be better resolved through a series of disparate electoral conflicts, each with limited reach, and not, as was the case in Heller, in a singular constitutional moment. Indeed, the ensuing years of substantial legal maneuvering set in motion by the Heller decision may be interpreted as representing the social welfare-decreasing aftermath predicted by the model, where, given this particular configuration of institutional bias parameters, conflict over fundamental rights becomes increasingly constitutionalized. Rendering the gun-control issue a purely constitutional matter in this way likely served only to increase the extent to which valuable scarce resources were dissipated in ideological conflict, and did not result in significant changes in the expected level of fundamental rights in society, in part, due to legislative actions by strategic, forward-looking politicians designed to offset the expected impact of greater judicial interference in the determination of fundamental rights.

The reconstitution of the judiciary in Syria

To further clarify the conclusions of the formal model, it is useful to consider how the analytic framework might be applied in areas of violent conflict, and, in particular, to think more carefully about how the analysis informs the establishment of peace and security in such areas. Take Syria, for instance, a country devastated by an (ongoing) armed conflict between forces loyal to the Ba'ath Party government and pro-reform protesters seeking the resignation of President Bashar al-Assad and an end to over four decades of Ba'ath Party rule. The conflict started on 15 March 2011, with popular demonstrations spreading nationwide by April 2011, demonstrations that were part of a broader Middle Eastern protest movement known as the Arab spring. In April 2011, Syria's army was deployed by President Assad to quell the uprising. Soldiers were ordered to open fire on demonstrators, killing a number of individuals in the southern city of Daraa [also spelled Deraa] and triggering days of violent unrest that steadily swept throughout the country over the following months, eventually devolving into a full-scale armed rebellion.

On 2 January 2013, the United Nations released an estimate that the civil war's death toll had exceeded 60,000; on 24 July 2013, that estimate was revised to over 100,000 . At this point, the conflict strongly resembles a sectarian civil war, with the leading government figures, mainly Shia Alawites, pitted against the pro-reform rebels, mainly Sunni Muslims. According to the United Nations High Commissioner for Refugees, approximately 1.7 million registered Syrian refugees have fled to neighboring countries to escape the violence, with another 200,000 individuals currently awaiting registration. ${ }^{20}$ In addition, tens of thousands of protesters have been imprisoned, and there are reports of widespread torture and psychological abuse in many of the state-run prisons. The humanitarian crisis has been further intensified by the widespread destruction and razing of residential areas by the Syrian government, where towns and villages across Latakia, Idlib, Hama, and Daraa governorates, for all practical purposes, have been completely emptied of their civilian populations.

The reconstitution of Syria will come about at some point in time,

but it is entirely possible that there may not be much of a judiciary left to strategize about. If so, the reconstitution of Syria may well result in an authoritarian democracy in which the judiciary is unlikely to deviate substantially from the ideological tenets promulgated by that regime. In all likelihood, this would be a mistake. The reconstruction of justice in Germany post-World War II is instructive. As Loewenstein contends, in many ways, the most exasperating aspect of the Nazi lega system lay in the fact that most of the Nazi regime's arbitrary and unjust acts were expressly couched in the form of an official statute, decree, or enactment, which, due to its formal character as a legislative act, was slavishly applied by the judiciary as "law," irrespective of whether the legal rule itself was unjust or arbitrary. ${ }^{21}$ The German judiciary was largely comprised of individuals unburdened by misgivings as to the intrinsic fairness of the legal rule to be applied in a given case, provided the rule itself was validly enacted by the authority of the State. They did not, for the most part, give pause to consider or question whether this authority was, in fact, legitimate in the first instance. With this in mind, it is, therefore, critically important, in establishing peace and security in Syria, to have a judiciary that possesses, not necessarily independence of office, but independence of character, and that is open to, as Loewenstein puts it, "the postulates of a humanitarian morality."

Notwithstanding the importance of an independent judiciary to the just and balanced exercise of political power, my analysis cautions that the reconstitution of the judiciary may itself become a strategic item. Specifically, those in power may argue publicly in support of an independent judiciary, knowing full well that any 
judicial interference that impairs their attempts to set policy for the country as a whole can be effectively offset by means of strategic, forward-looking legislative actions, as identified in the analysis. Alternatively, those in power may be perfectly willing to be viewed as embracing the virtues of a constitutional democracy, knowing full well that there exist back channels, including legal conflict (but also brute force), by which to establish and maintain ideology in the country.

An independent judiciary will often represent an important check on the authoritarian impulses of the ruling party, but the opposite may also be true. It is important to identify whether a push for an independent judiciary is an indication of a desire to promote and safeguard important individual freedoms and fundamental rights in society, or, instead, represents a power grab by those with a relative advantage in legal conflict seeking to exploit that advantage to modify or circumvent policy outcomes generated by an otherwise perfectly well-functioning democratic electoral process.

\section{Conclusion}

The formal analysis counsels against placing too much faith in either judicial or political processes. An independent and free-thinking judiciary is socially-beneficial if judges act to protect and defend important socially-optimal fundamental rights from the tyranny of the majority. The benefits of an independent judiciary are less clear, however, if legal conflict is employed as a means by which to promote, say, a religious ideology (e.g., Shi'a Islamic law or sharia) that runs contrary to the socially-optimal democratic will of the people. The analysis shows that it is important not to reflexively push for fundamental rights in society to be principally determined by the judiciary, because a relatively small, but powerful, subset of the population may use legal conflict as a means to impose an ideological agenda that diverges drastically from the socially-optimal outcome, in a manner no different than what can obtain with respect to any other form of nonelectoral (and possibly violent) intergroup conflict.

Notes

William C. Bunting is an economist at the American Civil Liberties Union (ACLU). All views expressed here are his own and not necessarily those of ACLU. He may be reached at <wcb231@nyu.edu $>$.

1. Rights considered fundamental in one country may be foreign to another. For instance, the constitutions of Canada, India, Israel, Mexico, and the United States guarantee freedom from double jeopardy, a right not provided under other legal systems. Similarly, many Americans consider gun rights to be fundamental, while other countries do not recognize them as fundamental rights.
2. Coase (1960). The framework is summarized in a set of assumptions adopted by Hoffman and Spitzer (1982): "(a) two agents to each externality (and bargain), (b) perfect knowledge of one another's (convex) production and profit or utility functions, (c) competitive markets, (d) zero transactions costs, (e) costless court system, (f) profit-maximizing producers and expected utility-maximizing consumers, (g) no wealth effects, (h) agents will strike mutually advantageous bargains in the absence of transactions costs."

3. Large literature: See, e.g., Wittman (1979), Gartzke (1999), Wagner (2000), Powell (2002), and Slantchev (2003). Seminal article: Fearon (1995). He dismisses the third explanation as empirically trivial because states can make side payments or take other actions that resolve the problem and allow ex ante bargains.

4. Powell (1996a; 1996b).

5. Fearon (1992).

6. Houantchekon (1994).

7. Social welfare is defined in a utilitarian manner as the population-weighted sum of individual utilities.

8. Extending the static model to a dynamic framework allows one to define judicial interference more precisely. Two measure of judicial activism can be defined: (1) judicial deference and (2) judicial diversity. In Bunting (2012), I show that parameter values exist such that, in equilibrium, a more diverse judiciary serves to increase overall welfare in society. I also show that electoral candidates announce policy platforms that perfectly offset any change in judicial deference. Social welfare is thus invariant with respect to changes in the judicial deference parameter. Unlike in the static model, a change in this particular judicial interference parameter has no long-run equilibrium effect on social welfare.

9. A sketch of the mathematics of the model of fundamental rights is provided in the Appendix. In particular, the functional form of the litigation success function is set forth, allowing the interested reader to interpret these two parameters in mathematical terms.

10. A similar result obtains with respect to changes in the extent to which ideological conflict is constitutionalized. The only difference is that increasing the extent to which conflict over fundamental rights is constitutionalized has no impact upon the range of feasible conflict outcomes. 
11. See the sketch of the proof provided in the Appendix. The full mathematical details are available from the author.

12. Downsian electoral competition: See, e.g., Enelow and Hinich (1982); Coughlin (1992); Persson and Tabellini (1999). The setup of the formal Downsian model of electoral competition is given in the Appendix. The politico-conflict equilibrium concept is defined, and a brief sketch of how various results are derived is provided.

13. Interestingly, in the game-theoretic literature on separation-of-powers, electoral actors strategically respond to increased judicial interference by shifting announced policy platforms closer to the judicial bliss point so as to avoid judicial veto, and not farther away from this bliss point, as in my model. See, e.g., Ingberman and Yao (1991); Ferejohn and Weingast (1992a; 1992b); Levy and Spiller (1994).

14. Greg Stohr, "Individual Gun Rights Protected, Top U.S. Court Says." http://www.bloomberg.com/apps/news?pid=newsarchive\&sid=aMQxuhnFkgSk [original: 26 June 2008; accessed 16 August 2013]

15. For example, immediately following the Heller decision, the NRA filed a lawsuit against the city of Chicago challenging its handgun ban, followed the next day by a lawsuit against the city of San Francisco seeking to overturn that city's ban on handguns in public housing. See "NRA Targets San Francisco, Chicago." CBS News [original: 27 June 2008; accessed: 10 September 2013].

16. "Roe ventured too far in the change it ordered. The sweep and detail of the opinion stimulated the mobilization of a right-to-life movement and an attendant reaction in Congress and state legislatures. In place of a trend 'toward liberalization of abortion statues' noted in Roe, legislatures adopted measure aimed at minimizing the impact of the 1973 ruling, including notification and consent requirements, prescriptions for the protection of fetal life, and bans on public expenditures for poor women's abortions" (Ginsburg, 1985, pp. 381-82).

17. Adam Liptak, "Supreme Court Gun Ruling Doesn't Block Proposed Controls." The New York Times [original: 18 December 2012; accessed: 10 September 2013].

18. Event timing in the model is as follows: The winning candidate enacts his or her announced policy platform, and the two adverse special interest groups then exert litigation effort to move the enacted policy platform closer to their respective bliss points.
19. Supporters of the Coasian approach to private property rights have afforded too much leeway to courts, construing judicial actors as unbiased, informed, incorruptible promoters of aggregate social welfare, when, in fact, the empirical evidence is mixed. Scholars have identified jurisdictions in which courts are highly-inefficient, politically-motivated, slow, or even corrupt (see, e.g., Johnson, et al. 2002; Buscagliaa, 2001; Djankov, 2003).

20. See http://data.unhcr.org/syrianrefugees/regional.php [accessed 16 August 2013]

21. Loewenstein (1948)

\section{References}

Bunting, W.C. 2012. "The Conflict over Fundamental Rights: A Dynamic Model." Unpublished Manuscript. < https://files.nyu.edu/wcb213/public/>

Buscagliaa, E. 2001. "An Analysis of Judicial Corruption and its Causes: An Objective Governing-Based Approach." International Review of Law and Economics. Vol. 21, No. 2, pp. 233-249.

Coase, R. 1960. "The Problem of Social Cost.” Journal of Law and Economics. Vol 3, No. 3, pp. 1-44

Coughlin, P.J. 1992. Probabilistic Voting Theory. New York: Cambridge University Press.

Djankov, S., R. La Porta, F. Lopez-de-Silanes, A. Shleifer. 2003. “Courts.” Quarterly Journal of Economics. Vol. 118, No. 2, pp. 453-517.

Enelow, J. and M.J. Hinich. 1982. "Non-Spatial Candidate Characteristics and Electoral Competition.” Journal of Politics. Vol. 44, No. 1, pp. 115-130.

Fearon, J.D. 1992. "War, Relative Power and Private Information," in The Annual Meeting of the International Studies Association, 31 March to 4 April 1992 Atlanta, GA.

Fearon, J.D. 1995. "Rationalist Explanations for War.” International Organization Vol. 49, No. 3, pp. 379-414.

Ferejohn, J.A. and B.R. Weingast. 1992a. "Limitation of Statutes: Strategic Statutory Interpretation.” Georgetown Law Journal. Vol. 80, No. 3, pp. 565-582.

Ferejohn, J.A. and B.R. Weingast. 1992b. "A Positive Theory of Statutory Interpretation." International Review of Law and Economics. Vol. 12, No. 2, pp. 263-279.

Gartze, E. 1999. "War is in the Error Term.” International Organization. Vol. 53, No. 3 , pp. $567-587$.

Ginsburg, R.B. (1985). "Some Thoughts on Autonomy and Equality in Relation to Roe v. Wade." North Carolina Law Review. Vol. 63, No. 2, pp. 375-386.

Hoffman, E. and M.L. Spitzer. 1982. "The Coase Theorem: Some Experimental Tests." Journal of Law and Economics. Vol. 25, No. 1, pp. 73-98. 
Houantchekon, L. 1994. "Electoral Competition with Outside Options.” Unpublished Manuscript. Department of Economics. Northwestern University.

Ingberman, D.E. and D.A. Yao. 1991. "Circumventing Formal Structure through Commitment: Presidential Influence and Agency Control.” Public Choice. Vol. 70, No. 2, pp. 151-179.

Johnson, S., J. McMillan, and C. Woodruff. 2002. "Property Rights and Finance." American Economic Review. Vol. 92, No. 5, pp. 1335-1356.

Levy, B. and P.T. Spiller. 1994. "The Institutional Foundations of Regulatory Commitment: A Comparative Analysis of Telecommunications Regulation." Journal of Law, Economics, and Organization. Vol. 10, No. 2, pp. 201-246.

Loewenstein, K. 1948. "Reconstruction of the Administration of Justice in American-Occupied Germany." Harvard Law Review. Vol. 61, No. 3, pp. 419-467.

Persson, T. and G. Tabellini. 1999. "The Size and Scope of Government: Comparative Politics with Rational Politicians." European Economic Review. Vol. 43, Nos. 4-6, pp. 699-735.

Powell, R. 1996a. "Bargaining in the Shadow of Power." Games and Economic Behavior. Vol. 15, No. 2, pp. 255-289.

Powell, R. 1996b. "Stability and the Distribution of Power." World Politics. Vol. 48, No. 2, pp. 239-267.

Powell, R. 2002. "Bargaining Theory and International Conflict." Annual Review of Political Science. Vol. 5, No. 1, pp. 1-20.

Wagner, R.H. 2000. "Bargaining and War." American Journal of Political Science. Vol. 44, No. 3, pp. 469-484.

Wittman, D. 1979. "How War Ends: A Rational Model Approach." Journal of Conflict Resolution. Vol. 23, No. 4, pp. 743-763.

\section{Appendix}

\section{Litigation success function}

Let the parameter $\tilde{\lambda} \in[0,1]$ denote the status quo level of fundamental rights in society. Likewise, let the parameter $c>0$ denote the marginal cost of litigation effort. There are two litigant types, indexed by $\tilde{i} \in\{0,1\}$. Type 0 litigants have a bliss point equal to 0 . Type 1 litigants have a bliss point equal to 1 .

The litigation success function is denoted by $p\left(e_{0}, e_{1}\right)$. If type 0 litigants commit effort $e_{0}$ to conflict and type 1 litigants commit effort $e_{1}$, then $\bar{\lambda}=\tilde{\lambda}-s$ obtains with probability $p\left(e_{0}, e_{1}\right)$ and $\bar{\lambda}=\tilde{\lambda}+s$ obtains with probability $1-p\left(e_{0}, e_{1}\right)$, where $p\left(e_{0}\right.$, $\left.e_{1}\right)$ in this analysis assumes the following functional form:

$$
p\left(e_{0}, e_{1}\right)=\frac{1}{2}+b\left[\theta e_{0}^{1 / 2}-e_{1}^{1 / 2}\right]
$$

with $b \in[0, \sqrt{2 c}]$. Note that the parameter $b>0$ is a measure of the effectiveness or decisiveness of litigation effort. In addition, the parameter $s>0$ is the judicial diversity parameter and defines the range of feasible judicial outcomes.

Exogenous political process

Define a social welfare function $(S W F)$ as the sum of individual expected welfare:

$$
\operatorname{SWF}\left(e_{0}, e_{1}\right)=U_{,}\left(e_{0}, e_{1}\right)+U_{1}\left(e_{0}, e_{1}\right) .
$$

Substituting equilibrium values $e_{0}^{*}(\tilde{\lambda})$ and $e_{1}^{*}(\tilde{\lambda})$, which are derived as the solution to a simple two-player conflict game and which can be expressed as a function of the status quo level of fundamental rights, $\tilde{\lambda}$, into the above expression, it can be shown that $S W F$ can be expressed as a function of announced policy platforms. Specifically,

$$
\operatorname{SWF}(\tilde{\lambda})=\tilde{\lambda}-\tilde{\lambda}^{2}+\frac{s^{2} b^{2}}{c}\left[\theta^{2} \widetilde{\lambda}^{2}-2\left(1+\theta^{2}\right) \tilde{\lambda}(1-\tilde{\lambda})+(1-\tilde{\lambda})^{2}\right]-s^{2} .
$$

Having expressed social welfare in terms of the model's parameters, including the parameter $s$, we can isolate the values of fundamental rights, $\tilde{\lambda}$, where increasing judicial diversity is social welfare-increasing by differentiating this expression with respect to the judicial diversity parameter, $s$, and then calculating the values of $\tilde{\lambda}$ that satisfy the following inequality:

$$
\frac{d \operatorname{SWF}(\vec{\lambda})}{d s}>0 .
$$

Next, set $\eta=c / b^{2}$. The parameter, $\eta>0$, is interpreted as a measure of the degree to which the conflict over fundamental rights is constitutionalized. In particular, as $\eta \Rightarrow 0$, the conflict is described as increasingly constitutionalized. That is, the conflict over fundamental rights is increasingly constitutionalized if litigation effort becomes less costly on the margin ( $c$ decreases) or more effective or decisive ( $b$ increases).

To isolate the values of fundamental rights, $\tilde{\lambda}$, where increasing the extent to which the legal conflict is constitutionalized is social welfare-increasing, we differentiate the social welfare expression $S F W(\tilde{\lambda})$ with respect to the 
constitutionalization parameter $\eta$ and calculate the values of $\tilde{\lambda}$ that satisfy the following inequality:

$$
\frac{d S F W(\tilde{\lambda})}{d \eta}<0
$$

\section{Endogenous political process}

The static model is extended by allowing the prevailing level of fundamental rights in society to be endogenously determined via electoral competition. In particular, assume that there are two electoral candidates, indexed by $k \in\{0,1\}$ and let $\tilde{\lambda}_{k}$ denote the type $k$ candidate's announced policy platform. Similarly, there are two voter types indexed by $j \in\{0,1\}$. Let a type $j$ voter's indirect preferences over an announced policy platform, $\tilde{\lambda}$, be represented by $W_{j}(\tilde{\lambda})$. Employing a well-known formal Downsian model of electoral competition, it can be shown that, given $\tilde{\lambda}_{l}$, the type $k$ candidate's probability of winning the election, $\pi_{k}\left(\tilde{\lambda}_{k}, \tilde{\lambda}_{l}\right)$, can be written as follows

$$
\pi_{k}\left(\tilde{\lambda}_{k}, \tilde{\lambda}_{l}\right)=\frac{1}{2}+\frac{\mathrm{X}}{\bar{\psi}}\left[W\left(\tilde{\lambda}_{k}\right)-W\left(\tilde{\lambda}_{l}\right)\right]
$$

where $W\left(\tilde{\lambda}_{k}\right) \equiv \sum_{j} \psi_{j} W_{j}\left(\tilde{\lambda}_{k}\right)$, and $\bar{\psi} \equiv \sum_{j} \psi_{j}$ is the average density across voter types. The parameters $X$ and $\psi_{j}$ are exogenously given. The parameter $\psi_{j}$ is a measure of voter-specific bias in favor of the type 1 candidate, and the parameter $X$ is a measure of the average relative popularity of the type 1 candidate.

The two electoral candidates, simultaneously and noncooperatively, choose their policy platforms so as to maximize the probability of winning the election. Specifically, candidate $k$ 's objective function is given by

$$
\Pi_{k}\left(\tilde{\lambda}_{k}\right)=\pi_{k}\left(\tilde{\lambda}_{k}, \cdot\right) R
$$

where the parameter $R>0$ denotes the expected value of exogenously-given ego rents. Given this setup, the equilibrium concept is defined as follows: The pair $\left(\tilde{\lambda}_{k}^{*}, \tilde{\lambda}_{l}^{*}\right)$ is a politico-conflict equilibrium if, given $\widetilde{\lambda}_{1}^{*}$, the type 0 candidate's announced policy platform, $\tilde{\lambda}_{0}$, solves

$$
\tilde{\lambda}_{0}^{*}=\arg \max _{\tilde{\lambda}_{0}}\left[\frac{1}{2}+\frac{X}{\bar{\psi}}\left[W\left(\tilde{\lambda}_{0}\right)-W\left(\tilde{\lambda}_{1}^{*}\right)\right]\right] R
$$

and, given $\tilde{\lambda}_{0}^{*}$, the type 1 candidate's announced policy platform, $\tilde{\lambda}_{1}$, solves

$$
\widetilde{\lambda}_{1}^{*}=\arg \max _{\tilde{\lambda}_{1}}\left[\frac{1}{2}+\frac{X}{\bar{\psi}}\left[W\left(\tilde{\lambda}_{1}\right)-W\left(\tilde{\lambda}_{0}^{*}\right)\right]\right] .
$$

The optimal policy platform, $\widetilde{\lambda}_{0}^{*}$, satisfies the following maximization problem:

$$
\max _{\tilde{\lambda}_{0}}\left\{\frac{X}{\bar{\psi}} \sum_{j} \psi_{j} W_{j}\left(\tilde{\lambda}_{0}\right)\right\} .
$$

The politico-conflict equilibrium is solved by observing that the problem is symmetric with respect to candidate type, and thus, the equilibrium policy platforms of the two electoral candidates converge to $\widetilde{\lambda}_{0}^{*}=\tilde{\lambda}_{1}^{*}=\tilde{\lambda}^{*}$.

The equilibrium policy response by electoral candidates to a change in judicial diversity or to a change in the extent to which the legal conflict is constitutionalized is derived by differentiating $\tilde{\lambda}^{*}$ with respect to $s$ and $\eta$, respectively. Likewise, the social welfare impact of such changes in these parameters characterizing the intergroup conflict over fundamental rights is derived by plugging $\tilde{\lambda}^{*}$ into the social welfare function, $S W F$, and differentiating this welfare function with respect to $s$ and $\eta$, respectively. 